\title{
Psychopharmacological Profile of the Water Extract of Gardenia jasminoides and Its Constituents, Genipin and Geniposide, in Mice
}

\author{
Ji Young Chol, Ike Dela Pena, Jong Hyun Chol, Seo Young Yoon, Dong Sool Yım, Yong Soo LeE ${ }^{\text {, }}$ \\ Kwang Ho Ko${ }^{2}$, Chan Young SHIN ${ }^{3}$, Jong Hoon $\mathrm{Ryu}^{4}$, Won Ki Kıм${ }^{5}$, and Jae Hoon CHeONG* \\ Uimyung Institute for Neuroscience, Sahmyook University, Seoul 139-742, Korea \\ ${ }^{1}$ Department of Pharmacology, College of Pharmacy, Duksung Women's University, Seoul 132-714, Korea \\ ${ }^{2}$ Department of Pharmacology, College of Pharmacy, Seoul National University, Seoul 139-742, Korea \\ ${ }^{3}$ Department of Pharmacology, College of Medicine, Konkuk University, Seoul 143-701, Korea \\ ${ }^{4}$ Department of Oriental Pharmaceutical Science, College of Pharmacy, KyungHee University, Seoul 130-701, Korea \\ ${ }^{5}$ Department of Neuoscience, College of Medicine, Korea University, Seoul 136-71, Korea
}

(Received April 28, 2008; Accepted May 29, 2008)

\begin{abstract}
Gardenia jasminoides ( $G$ jasminoides) is traditionally used to treat insomnia, jaundice, emotional disorders, hepatic disease, and inflammatory disease. Previously, we found that geniposide and the water extract of $\mathrm{G}$. jasminoides increased $\mathrm{Cl}^{-}$influx in neuroblastoma. Here we examined the psychopharmacological activities of $G$. jasminoides and its constituents. $G$. jasminoides extract was orally administered at 100 and $200 \mathrm{mg} / \mathrm{kg}$, and genipin and geniposide were intraperitoneally injected at 2, 10, and $20 \mathrm{mg} / \mathrm{kg}$. G jasminoides extract $(200 \mathrm{mg} / \mathrm{kg})$ significantly decreased total open field activity but increased rearing activity in the center of the open field, suggesting an increase in exploratory activity. Genipin and geniposide did not change open field activity, but geniposide $(20 \mathrm{mg} / \mathrm{kg})$ increased rearing activity in the central area. The extract $(200 \mathrm{mg} / \mathrm{kg})$ significantly decreased rotarod and wire-balancing activity, but genipin and geniposide did not. No compounds influenced thiopental-induced sleeping or electroshock-induced seizures. The extract $(200 \mathrm{mg} / \mathrm{kg})$ significantly increased staying time in the open arms of the elevated plus maze and the entry ratio into the open arms, and geniposide $(20 \mathrm{mg} / \mathrm{kg})$ also increased open arm entry. Electroshock stress decreased open arm activity, but the extract and geniposide $(20 \mathrm{mg} / \mathrm{kg})$ significantly reversed that effect. This results indicate that $G$ jasminoides extract and geniposide alleviated anxiety with greater efficacy in stressed animals than normal animals.
\end{abstract}

Keywords: Gardenia jasminoides, geniposide, genipin, anxiety, behavior

\section{INTRODUCTION}

Gardenia jasminoides ( $G$ jasminoides) is an important medicinal herb in traditional Korean medicine. The fruit of $G$ jasminoides is widely employed in the treatment of inflammation, hypertension, jaundice, headache, edema and hepatic disorders (Koo et al., 2004; Shin et al., 2003). Geniposide and genipin are the major iridoid glycoside compounds existing in the fruit of gardenia and are responsible for its pharmacological activities such as

\footnotetext{
${ }^{*}$ Corresponding author

Tel: +82-2-3399-1605, Fax: +82-2-3399-1617

E-mail: cheongjh@syu.ac.kr
}

hepatoprotective (Cgang, 1988), antithrombotic (Suzuki et al., 2001), neuroprotective (Sakura et al., 2001), neuritogenic (Yamazaki et al., 1996) and anti-inflammatory effects (Koo et al., 2004) and protective activity against oxidative damage (Okada et al., 2007), Oral administration of the water extracts of Gardeniae fructus and geniposide increased social interaction time in mice (Toriizuka et al., 2005). These results indicate that Gardeniae fructus and geniposide may exhibit anxiolytic activity.

Both pharmacological and genetic studies associate deficits in inhibitory neurotransmission in the mammalian forebrain with increased anxiety-related behavior, and $\gamma$ amino-butyric acid (GABA), the main inhibitory neurotransmitter in the mammalian central nervous system, 
activates chloride ion channel and cause hyperpolarization of the neuron (Depino et al., 2008). The benzodiazepine-GABA system plays an important role in anxiety, benzodiazepine agonists acting at their site in the $\mathrm{GABA}_{A}$ receptor complex produce anxiolytic effect (Argyropoulos et al., 2000). Initially, we found that geniposide and water extract of $\mathrm{G}$ jasminoides increased $\mathrm{Cl}^{-}$influx in neuroblastoma cell. Thus, $G$ jasminoides and its constituents may influence psychological activities. In this study, we tested the psychopharmacological activities of $G$ jasminoides and its constituents.

\section{MATERIALS AND METHODS}

\section{Animals}

The male ICR mice $(20-25 \mathrm{~g})$ used in this study were obtained from Hanlim experimental animal Co. (Hwasung, Korea). All animals were maintained on a standard right-dark cycle (6 A.M.-6 P.M.), at ambient temperature $\left(22 \pm 2^{\circ} \mathrm{C}\right)$ and humidity $(55 \pm 5 \%)$. They had free access to food and water throughout the experiments. The animals were stabilized for 1 week in our animal room. The G. fructus extract was orally injected at 100 and $200 \mathrm{mg} /$ $\mathrm{kg}$. Genipin and geniposide were intraperitoneally injected at 2, 10 and $20 \mathrm{mg} / \mathrm{kg}$. Animals of control group were intraperitoneally injected with the same volume of saline. Diazepam was intraperitoneally injected to mice in the positive control group.

\section{Materials}

We used dried fruit of $G$ jasminoides which was obtained from herbal suppliers in Seoul. Stir-baked Fructus gardeniae was boiled in water three times, and the resulting decoctions pooled. This solution was then clarified by centrifugation and filtration. The resulting primary extract was lyophilized. Geniposide was supplied by Natural product laboratory of Sahmyook university. Geniposide was isolated from the water extract of $G$ jasminoides. Diazepam was purchased from Samjin Pharm. Co. (Seoul, Korea) and thiopental sodium was purchased from Choongwae Pharm. Co. (Seoul, Korea). Genipin and other materials were purchased from Sigma-Aldrich Co. (St. Louis, Mo, USA).

\section{Intracellular $\mathrm{Cl}^{-}$measurement}

Relative changes in intracellular $\mathrm{Cl}^{-}$concentration $\left(\left[\mathrm{Cl}^{-}\right]\right)$ in IMR-32 human neuroblastoma cells were monitored using a $\mathrm{Cl}^{-}$-sensitive indicator, $\mathrm{N}$-(6-methoxyquinolyl) acetoetylester (MQAE) (West and Molly, 1996). Briefly, cells were washed twice and re-suspended at a concentration of $4 \times 10^{5} \mathrm{cells} / \mathrm{ml}$ in Hank's solution. Cells were incubated with MQAE dye overnight at a final concentration of $5 \mathrm{mM}$ at room temperature to load the dye into the cells. Fluorescence (excitation wavelength set at $365 \mathrm{~nm}$ and emission wavelength at $450 \mathrm{~nm}$ ) was monitored in a well-stirred cuvette. All fluorescence values were corrected for background fluorescence, which was separately determined using a HEPES-buffered KSCN solution containing $5 \mu \mathrm{M}$ valinomycin to maximally quench the MQAE ion-selective signal (Shumaker et al., 1999). In separate experiments the base line was determined by bathing the cells with $\mathrm{Cl}^{-}$-free $\left(\mathrm{KNO}_{3}\right)$ solution containing $10 \mathrm{mM}$ tributyltin and $10 \mathrm{mM}$ nigericin.

\section{Behavioral apparatus}

The behavioral changes of animals were monitored automatically using a computerized EthoVision system (Noldus IT b.v., Netherlands). In the locomotor activity, rota-rod test, balanced wire test and elevated plus-maze tests, the behavioral parameters were analyzed by automatic systems.

\section{Locomotor activity}

The apparatus consisted of 9 black plastic boxes $(47 \times 47 \mathrm{~cm})$, and the field was bordered by $42-\mathrm{cm}$-high side walls. The total moved distance, total movement time and turn angles were monitored for 30 minutes after administration (Kim et al., 2003; Noldus et al., 2001).

\section{Rota-rod test}

Twenty-four hours before the experiment, all mice were habituated to running in a rota-rod at a speed of $60 \mathrm{rpm}$ until they could remain there for 60 seconds without falling. The latency to fall and falling frequency were recorded with a stopwatch (Lee et al., 2005; Farkas et al., 2005).

\section{Balanced wire test}

Like the rota-rod test, rats were habituated to grasp horizontal wires $(5 \mathrm{~mm}$ diameter, $150 \mathrm{~cm}$ length, elevated $80 \mathrm{~cm}$ above the floor) with their forepaws and tails. The balanced wire test was carried out for $20 \mathrm{~min}$, and the latency time to fall and falling frequency were recorded (Lee et al., 2006).

\section{Thiopental-induced sleep}

Male ICR mice were treated subcutaneously with thiopental sodium $(50 \mathrm{mg} / \mathrm{kg}) 30 \mathrm{~min}$ after intraperitoneal administration of the test materials. The time between the loss and recovery of the righting reflex was measured. Animals were observed for 30 min following thio- 
pentalinjection. If no recovery was seen, sleep time was taken as $\mathbf{3 0 ~} \mathrm{min}$ for calculation purposes (Farkas et al., 2005).

\section{Anticonvulsive activity test (electroshock model)}

A constant current stimulator was used to evoke seizure, as determined by overt hind-limb extension. Animals were given electroshocks for $1 \mathrm{sec}$ to determine the current-convulsion relationship. If an animal showed convulsion, the next animal was electrically shocked in $3 \mathrm{~mA}$ decrements of the current intensity. If this did not induce a convulsion in the animal, the next animal was electro shocked with $3 \mathrm{~mA}$ increments of the current intensity. This resulted in an establishment of a current-convulsion relationship. For each treatment group, 20-30 pups were prepared and the animals sacrificed immediately following determination of the electroshock seizure threshold (Park et al., 2007).

\section{Induction of anxiety by electro-shock stress}

The mice were exposed to electroshocks with an intensity of $0.5 \mathrm{~mA}$ ( $1 \mathrm{sec}$ duration; $20 \mathrm{sec}$ inter-shock interval) for 5 minutes (Lee et al., 2006). As soon as the final stress was loded, the animals were placed in the central square after measuring stress related activity and allowed to explore the maze freely for 5 minutes.

\section{Elevated plus-maze test}

The apparatus consisted of two open arms $(30 \times 6 \mathrm{~cm}$ in mice), alternating at right angles, with two arms enclosed by high walls of $20 \mathrm{~cm}$. Each four arms has a delimited central area of $6 \times 6 \mathrm{~cm}$. The whole apparatus was placed $50 \mathrm{~cm}$ above the floor. Animals were placed in the central square after measuring stress related activity and allowed to explore the maze freely for 5 minutes. The parameters measured were the times spent in open and closed areas (Kim et al., 2003; Noldus et al., 2001).

\section{Statistical analysis}

Data are expressed as the mean \pm S.E.M. ANOVA was used to compare the scores among groups for one variable. This was followed by post hoc comparisons using the Newman-Keuls test. Differences with $p<0.05$ were considered to be statistically significant.

\section{RESULTS}

\section{$\mathrm{Cl}^{-}$ion inlux in neuroblastoma cells}

Treatment with geniposide dramatically and dosedependently increased intracellular $\mathrm{Cl}^{-}$influx (Fig. 1), as did $G$ jasminoides extract, but genipin did not.

\section{The locomotor activities}

Locomotor activity included the total distance, duration of movement, total degrees of turn angles, and rearing frequency in the total and central areas (Fig. 2 and 3). Diazepam significantly decreased locomotor activity. $G$ jasminoides extract decreased the distance, movement duration, and total turn angle degree in the total area, but increased rearing frequency in the central area, with less efficacy than diazepam. Genipin and geniposide did not significantly affect locomotor activity.

\section{Activities on the rota-rod and the balanced wire}

Motor coordination was evaluated using the rota-rod test and the balanced wire. Diazepam significantly shortened the running time on the rota-rod and the balanced wire and
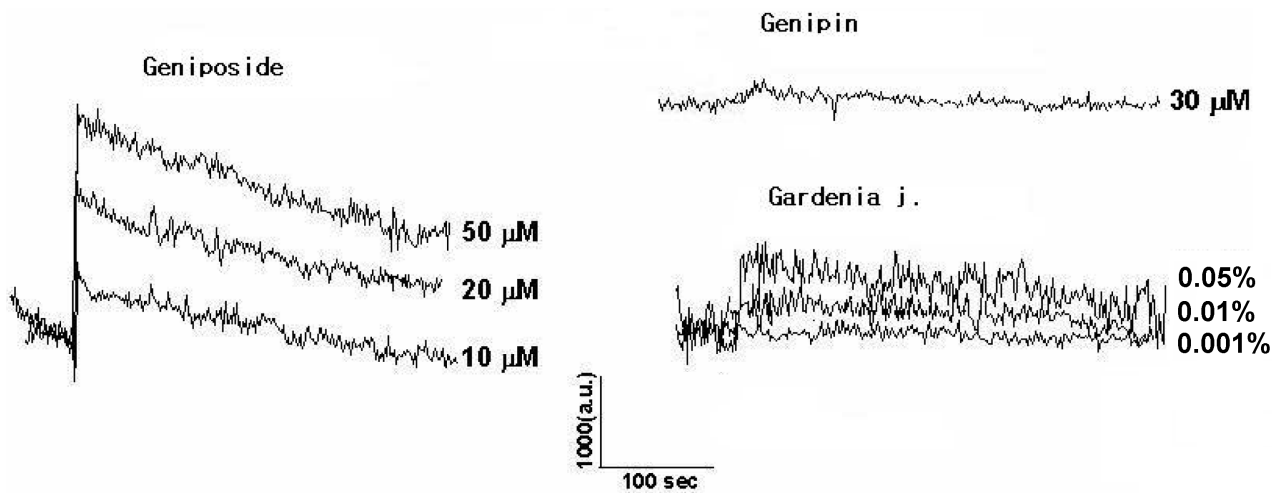

Fig. 1. Effects of $G$. jasminoides extract, genipin and geniposide on $\left[\mathrm{Cl}^{-}\right]_{\mathrm{i}}$ in neuroblastoma cells. Fluorescence was monitored in the excitation wavelength at $365 \mathrm{~nm}$ and the emission wavelength at $450 \mathrm{~nm}$ using the $\mathrm{Cl}^{-}$-sensitive indicator, $\mathrm{N}$-(6-methoxyquinolyl) acetoetylester (MQAE). Contents of influx $\mathrm{Cl}^{-}$ion was expressed as a peak (a.u.). 

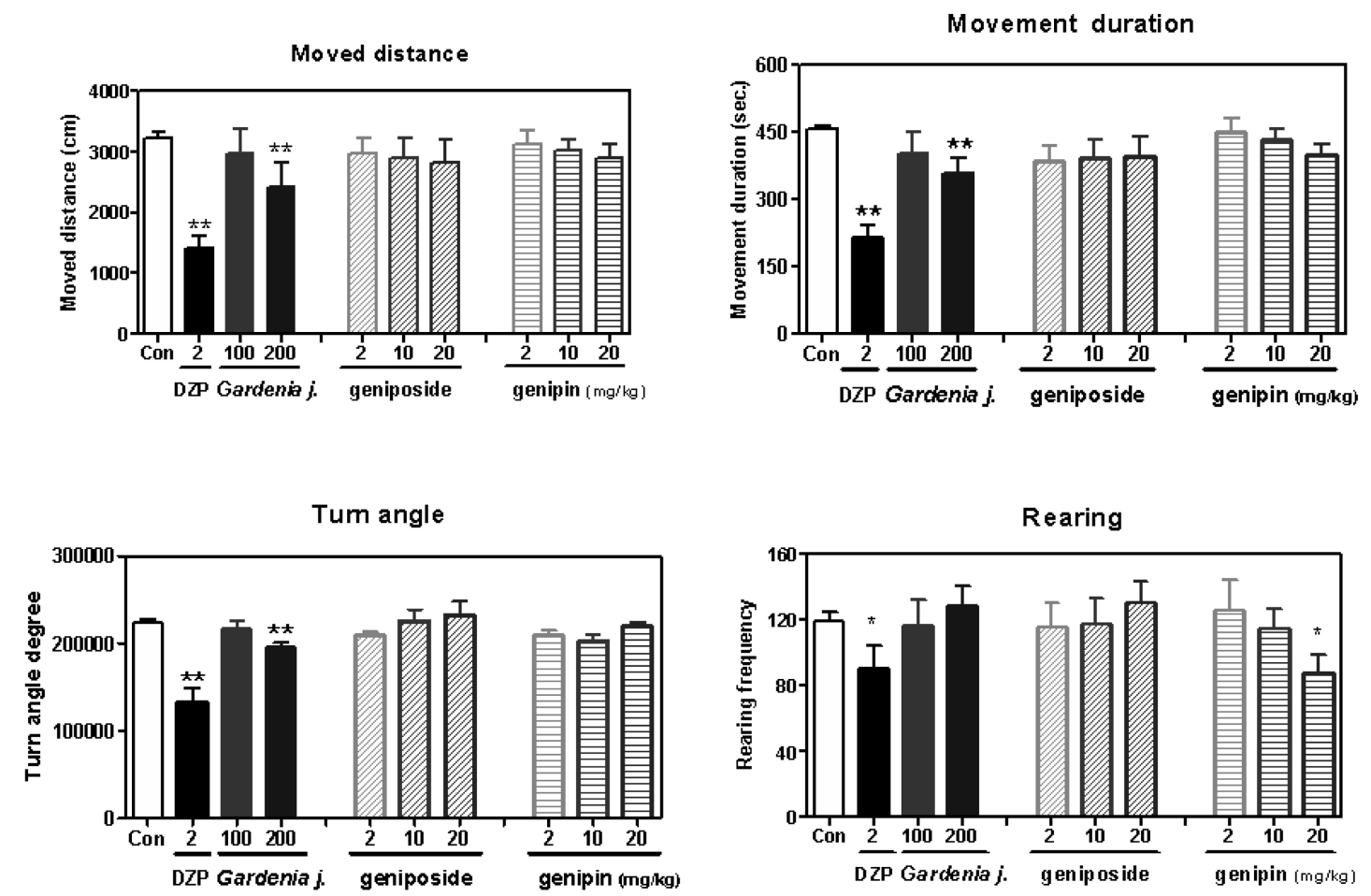

Fig. 2. Effects of $G$. jasminoides extract, genipin and geniposide on locomotor activity (total area) in mice ( $n=9)$. Each bar represents the mean \pm S.E.M of the moved distances, movement durations, turn angle degrees or rearing frequencies for 10 minutes. $\left({ }^{*} p<0.05\right.$, ${ }^{* *} p<0.01$ versus control group). DZP : diazepam.
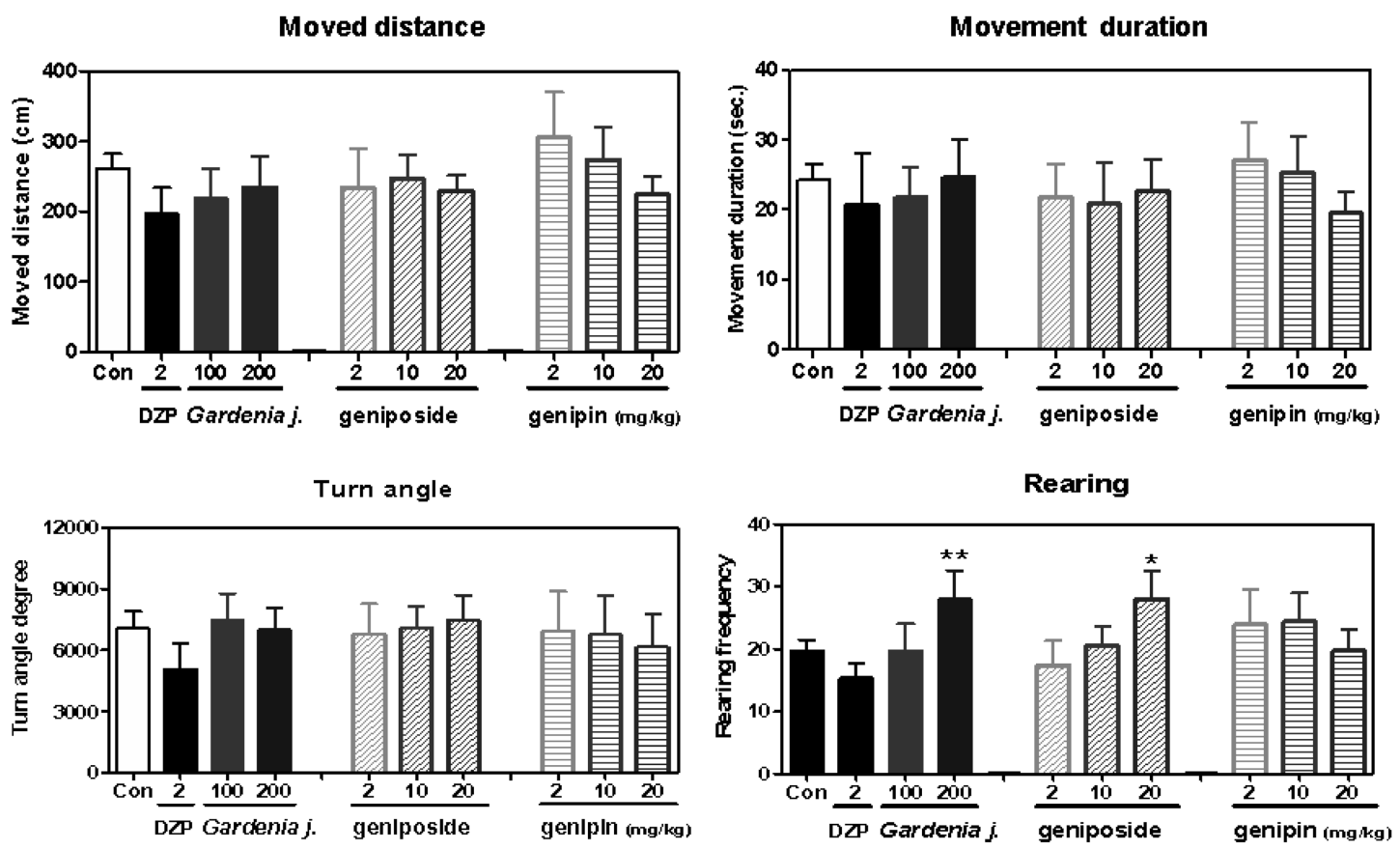

Fig. 3. Effects of $G$ jasminoides extract, genipin and geniposide on locomotor activity (central area) in mice ( $n=9)$. Each bar represents the mean \pm S.E.M of the moved distances, movement durations, turn angle degrees or rearing frequencies for 10 minutes. $\left({ }^{*} p<0.05,{ }^{* *} p<0.01\right.$ versus control group). DZP : diazepam. 

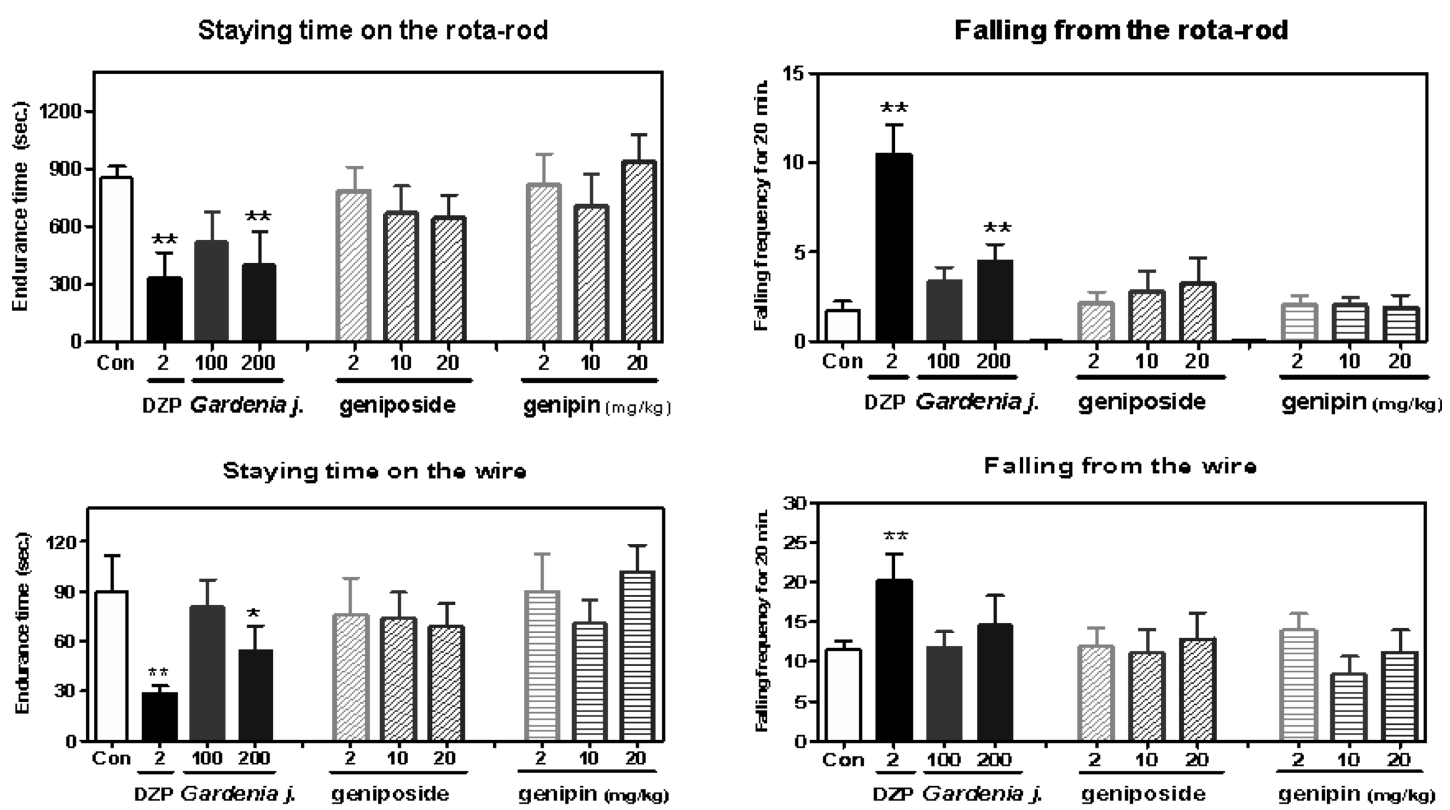

Fig. 4. Effects of $G$ jasminoides extract, genipin and geniposide on activity on the rotarod or wire in mice $(n=10)$. Each bar represents the mean \pm S.E.M of the endurance times or falling frequencies for 20 minutes. $\left({ }^{*} p<0.05,{ }^{* *} p<0.01\right.$ versus vehicle control group). DZP : diazepam.
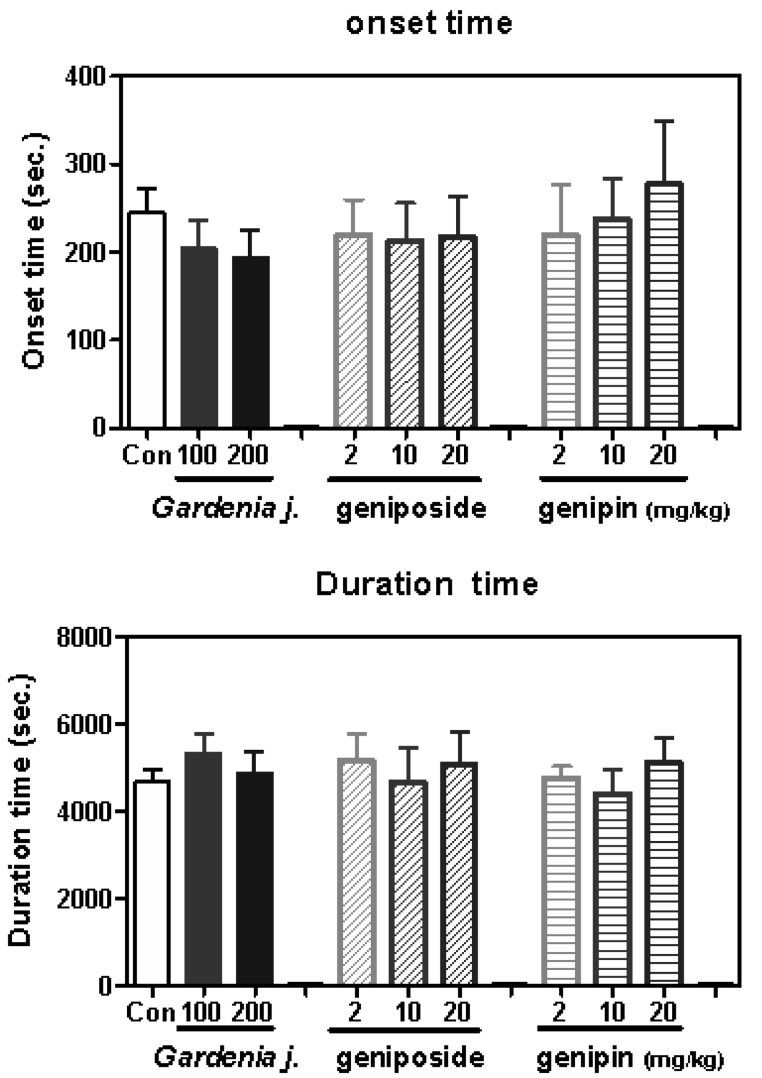

Fig. 5. Effects of $G$ jasminoides extract, genipin and geniposide on thiopental induced sleep in mice $(n=10)$. Each bar represents the mean \pm S.E.M of the onset times or the duration times. ( ${ }^{*} p<0.05,{ }^{* *} p<0.01$ versus vehicle control group). increased falling frequencies from both (Fig. 4). The extract also significantly decreased running time on the rota-rod and the wire and increased falling frequency from the rotating rod, but with less efficacy than diazepam. Geniposide and genipin did not affect these activities.

\section{Thiopental-induced sleeping}

Administration of $G$ jasminoides extract, geniposide, and genipin did not significantly change thiopental-

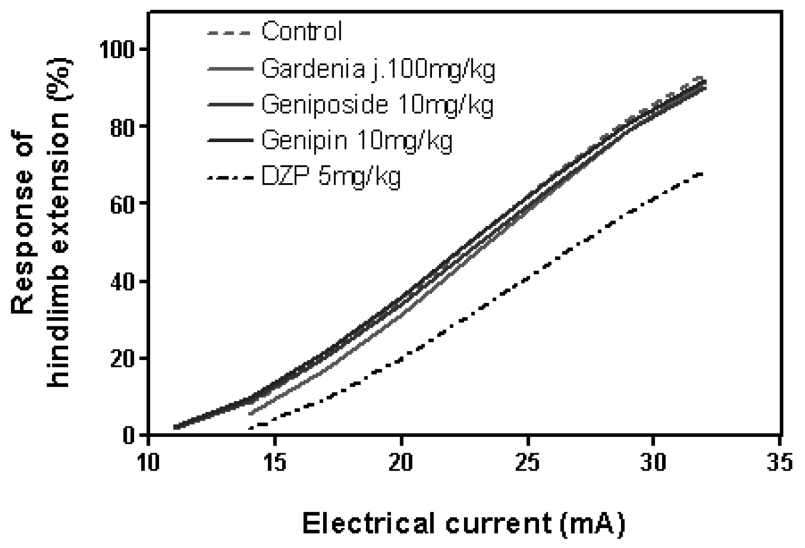

Fig. 6. Effects of $G$ jasminoides extract, genipin and geniposide on electroshock convulsion in mice. Each line represents the mean \pm S.E.M of $\%$ of animals with hind-limb extension by currents (pulse width- $0.5 \mathrm{~ms}$, frequency- 100 pulses $/ \mathrm{sec}$. shock duration-1 sec.). DZP : diazepam. 
A

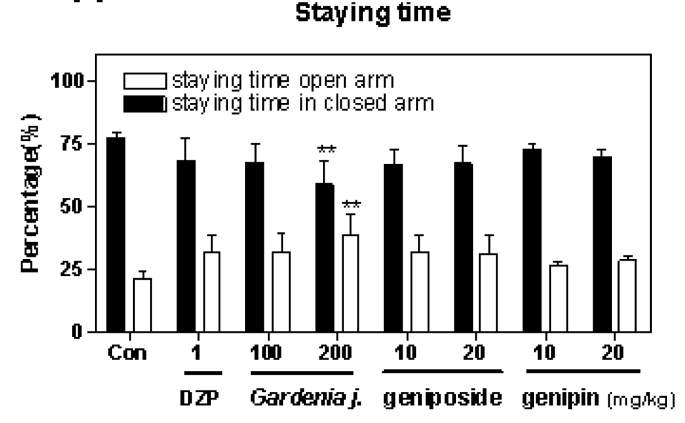

Entry ratio

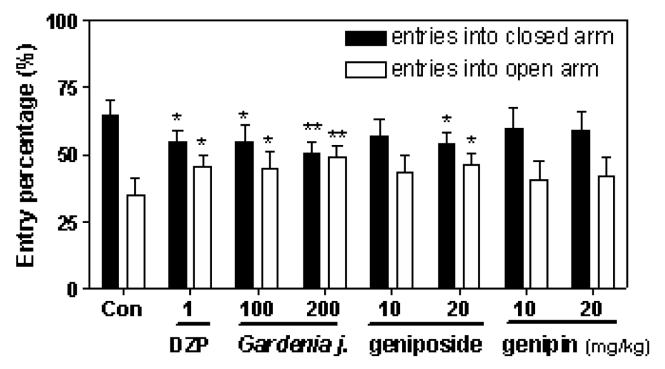

B

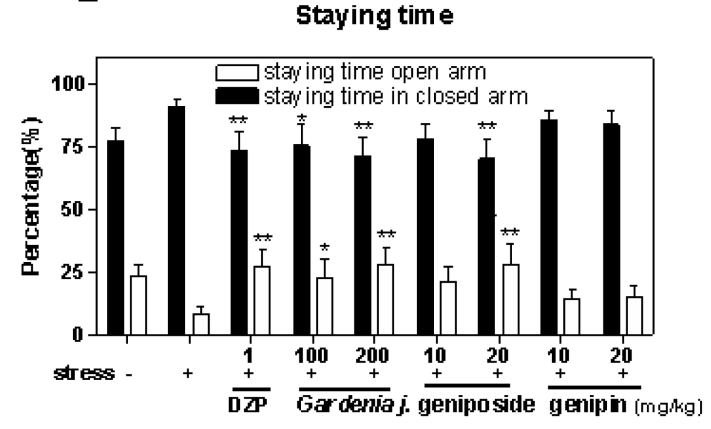

Entry ratio

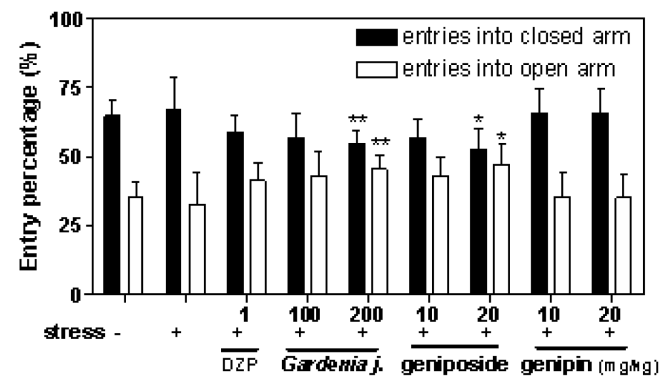

Fig. 7. Effects of $G$ jasminoides extract, genipin and geniposide on activity on elevated plus maze in mice ( $n=10)$. A : Activity on elevated plus maze in normal mice. B : Activity on elevated plus maze in mice exposed to electroshock stress. Each bar represents the mean \pm S.E.M of $\%$ of the time spent in arms and frequency entered into arms. ( ${ }^{\star} p<0.05,{ }^{* *} p<0.01$ versus control group). DZP : diazepam.

induced sleeping or the seizure response induced by electro-shock (Fig. 5 and 6).

\section{Activities in plus maze}

Mice treated with $G$ jasminoides extract $(200 \mathrm{mg} / \mathrm{kg})$ spent more time in the open arms than saline-treated mice and entered more frequently into the open arms (Fig. 7A). Administration of diazepam (1 mg/kg) or geniposide $(20 \mathrm{mg} / \mathrm{kg})$ also significantly increased open arm entry frequency. Electroshock stress shortened the staying time in the open arms, a sign of anxiety (Fig. 7B). However, stressed mice treated with $G$ jasminoides extract $(100 \mathrm{mg} / \mathrm{kg}$ and $200 \mathrm{mg} / \mathrm{kg})$ and geniposide $(20$ $\mathrm{mg} / \mathrm{kg}$ ) significantly spent more time in the open arms and showed increased open arm entry ratios compared to the stressed mice treated with saline only. Thus, $G$ jasminoides extract and geniposide showed greater anxiolytic activity in stressed animals than the normal animals.

\section{DISCUSSION}

$G$ jasminoides extract decreased movement in the open field but increased exploratory activity, such as rear- ing frequency in the central area. The extract also decreased rota-rod and balance wire activity but did not influence sleeping or convulsions. Thus, $G$ jasminoides extract may induce calmness or myorelaxation without excessive sedation or anti-convulsiveness, or blunting exploratory activity or curiosity. Most anxiolytic drugs, such as diazepam, have sedative and myorelaxing effects (Argyropoulos et al., 2000).

In this study, we show similar effects for $G$ jasminoides extract. Calming and exploratory behavior were used as parameters of anxiety level (Depino et al., 2008; Aron et al., 1971). The elevated plus maze test is used to evaluate anxiety-related behaviors and it involves a conflict between the rodent's desire to explore a novel environment and anxiogenic elements, such as elevation and an unfamiliar, brightly illuminated area (Lister, 1987). Increases in open-arm activity (i.e. percentage of entries made into and percentage of time spent on the open arms) indicate anxiety reduction. The anxiolytic activity of $G$ jasminoides extract was more effective in animals stressed by electroshock than the normal animals. Geniposide induced behavioral changes in the elevated plus maze test only, but dramatically increased Clinflux (only 
at a high dose). Thus, $\mathrm{Cl}^{-}$influx by $\mathrm{G}$. jasminoides extract and geniposide played a role in their anxiolytic activity, as suggested by other reports (Toriizuka et al., 2005).

Ligand binding at the benzodiazepine binding site on the $\mathrm{GABA}_{\mathrm{A}}$ receptor complex produces anxiolysis, anticonvulsion, muscle relaxation, and sedation (Wang et al., 1999). Binding of GABA to the $\mathrm{GABA}_{A}$ receptor activates chloride ion influx through the channel, and ligands for the benzodiazepine binding site modulate the inhibitory effects of GABA (Wang et al., 1999). Classical benzodiazepine anxiolytics (e.g., diazepam) are the most widely prescribed drugs for the treatment of anxiety disorders (Handley, 1994). In this study, diazepam exhibited stronger sedative and myorelaxing effects than $G$ jasminoides extract, but $G$ jasminoides extract had stronger anxiolytic activity than diazepam. The stimulation of GABA /benzodiazepine receptors in the basolateral amygdala by local administration of midazolam and muscimol impaired inhibitory avoidance acquisition, but did not change escape behavior in the elevated T maze (Duzzioni et al., 2008). Benzodiazepine agonist microinjection into the Acb nucleus does not alter open field behavior or other anxiety models, such as the light-dark box and Vogel conflict test, because $\mathrm{GABA}_{\mathrm{B}}$ receptors may be more important in fear/anxiety regulation than $\mathrm{GABA}_{\mathrm{A}}$ receptors (Lopes et al., 2007). However, the mechanism of anxiolytic action of $G$ jasminoides extract and geniposide requires further study.

In summary, we showed that $G$ jasminoides extract and geniposide alleviate anxiety, especially stressinduced anxiety. Moreover, the anxiolytic activity of $G$ jasminoides extract and geniposide is related to $\mathrm{Cl}^{-}$influx.

\section{ACKNOWLEDGEMENTS}

This research was supported by a grant (No. 07092 Hanyakjae332) from SHM program of Korean Food and Drug Administration.

\section{REFERENCES}

Argyropoulos, S. V., Sandford, J. J., and Nutt, D. J. (2000) The psychobiology of anxiolytic drugs. Part 2: pharmacological treatments of anxiety. Pharmacol. Ther. 88, 213-227.

Aron, C., Simon, P., Larousse, C., and Boissier, J. M. (1971) Evaluation of a rapid technique detecting minor tranquillizers. Neuropharmacol. 10, 459-469.

Chang, I. M. (1998) Liver-protective activities of aucubin derived from traditional oriental medicine. Res. Commun. Mol. Pathol. Pharmacol. 102, 189-204.

Depino, A. M., Tsetsenis, T., and Gross, C. (2008) GABA homeostasis contributes to the developmental programming of anxiety-related behavior. Brain Res. 1210, 189-199.

Duzzioni, M., Calixto, A. V., Duarte, F. S., and Lima, T. C. M. (2008) Modulation of anxiety in rats evaluated in the elevated T-maze: Evidence of the relationship between substance $P$ and diazepam. Behav. Brain Res. 187, 140-145.

Farkas, S., Berzsenyi, P., Kárpáti, E., Kocsis, P., and Tarnawa, I. (2005) Simple pharmacological test battery to assess efficacy and side effect profile of centrally acting muscle relaxant drugs. J. Pharmacol. Toxicol. Methods 52, 264-273.

Handley, S. (1994) Future prospects for the pharmacological treatment of anxiety. CNS Drugs 2, 397-414.

Kim, M. K., Yu, G. Y., Tan-Lee, B. S., Oh, H. J., Dong, K. W., Jeong, S. H., Han, S. W., and Cheong, J. H. (2003) Antistress effect of Pyroligneous liquid in SD rats and ICR mice. J. Appl. Pharmacol. 11, 249-256.

Koo, H. J., Song, Y. S., Kim, H. J., Lee, Y. H., Hong, S. M., Kim, S. J., Kim, B. C., Jin, C., Lim, C. J., and Park, E. H. (2004) Antiinflammatory effects of genipin, an active principle of gardenia. Eur. J. Pharmacol. 14(495), 201-8.

Lee, G. S., Choi, J. Y., Ko, H. S., Tan-Lee, B. S., Yu, G. Y., Park, H. G. Kim, M. K., Ryu, J. H., Jung, I. K., and Cheong, J. H. (2006) Stress-reducing Effects of Brown Rice Koji. Food Sci. Biotech. 15, 63-69.

Lister, R. G. (1987) The use of a plus-maze to measure anxiety in the mouse, Psychopharmacol. (Berl) 92, 180-185.

Lopes, A. P. F., Cunha, I. C., Steffens, S. M., Ferraz, A., Vargas, J. C., Lima, T. C. M., Neto, J. M., Faria, M. S., and Paschoalini, M. A. (2007) GABAA and GABAB agonist microinjections into medial accumbens shell increase feeding and induce anxiolysis in an animal model of anxiety. Behavioural Brain Res. 184, 142-149.

Noldus, L. P. J. J., Spink, A. J., and Tegelenbosch, A. J. (2001) EthoVision: A versatile video tracking system for automation of behavioral experiments. Psychonomic Society 33, 398-414.

Okada, K., Shoda, J., Kano, M., Suzuki, S., Ohtake, N., Yamamoto, M., Takahashi, H., Utsunomiya, H., Oda, K., Sato, K., Watanabe, A., Ishii, A., Itoh, K., Yamamoto, M., Yokoi, T., Yoshizato, K., Sugiyama, Y., and Suzuki, H. (2007) Inchikoto, a herbal medicine, and its ingredients dually exert Mrp2/ MRP2-mediated choleresis and Nrf2-mediated antioxidative action in rat livers. Am. J. Physiol. Gastrointest. Liver Physiol. 292, G1450-G1463.

Park, H. G., Yoon, S. Y., Choi, J. Y., Lee, G. S., Shin, C. Y., Son, K. H., Lee, Y. S., Kim, W. K., Ryu, J. H., Ko, K. H., and Cheong, J. H. (2007) Anticonvulsant effect of wogonin isolated from Scutellaria baicalensis. Eur. J. Pharmacol. 574, 112-119.

Sakura, M., Chiba, K., and Mohri, T. (2001) Prevention of the neurotoxicity of the amyloid $\beta$ protein by genipin. Biol. Pharm. Bull. 24, 1454-1455.

Shin, Y. W., Kim, D. H., and Kim, N. J. (2003) Studies on the processing of crude drugs(VII) : on the constituents and biological activities of gardeniae fructus by processing. Kor. J. Pharamcogn. 34, 45-54.

Shumaker, H., Amlal, H., Frizzell, R., Ulrich, C. D. Jr., and Soleimani, M. (1999) CFTR drives $\mathrm{Na}^{+}-\mathrm{nHCO}^{-}$cotransport in pancreatic duct cells: a basis for defective $\mathrm{HCO}^{-}$secretion in 
CF. Am. J. Physiol. 276, C16-25.

Suzuki, Y., Kondo, K., Ikeda, Y., and Umemura, K. (2001) Antithrombotic effect of geniposide and genipin in the mouse thrombosis model. Planta Medica 67, 807-810.

Toriizuka, K., Kamiki, H., Ohmura, N., Fujii, M., Hori, Y., Fukumura, M., Hirai, Y., Isoda, S., Nemoto, Y., and Ida, Y. (2005) Anxiolytic effect of Gardeniae Fructus-extract containing active ingredient from Kamishoyosan (KSS), a Japanese traditional Kampo medicine. Life Sci. 77, 3010-3020.

Wang, Q., Han, Y., and Xue, H. (1999) Ligands of GABAA receptor benzodiazepine binding site. CNS Drug Rev. 5, 125144.
West, M. R. and Molloy, C. R. (1996) A microplate assay measuring chloride ion channel activity. Anal. Biochem. 241, 5158.

Yamamoto, M., Miura, N., Ohtake, N., Amagaya, S., Ishige, A., Sasaki, H., Komatsu, Y., Fukuda, K., Ito, T., and Terasawa, K. (2000) Genipin, a metabolite derived from the herbal medicine Inchin-ko-to, and suppression of Fas-induced lethal liver apoptosis in mice. Gastroenterol. 118, 380-389.

Yamazaki, M., Chiba, K., and Mohri, T. (1996) Neuritogenic effect of natural iridoid compounds on PC12h cells and its possible relation to signaling protein kinases, Biol. Pharm. Bull. 19, 791-795. 